Just a joke : Psychogenesis of humor in alcohol advertisements

Seppänen, Janne

2018-02

Seppänen , J , Hellman , M \& Katainen , A 2018 , ' Just a joke : Psychogenesis of humor in alcohol advertisements ' , Scandinavian Psychoanalytic Review , vol. 40 , no. 2 , pp.

138-146 . https://doi.org/10.1080/01062301.2018.1439214

http://hdl.handle.net/10138/309252

https://doi.org/10.1080/01062301.2018.1439214

Downloaded from Helda, University of Helsinki institutional repository.

This is an electronic reprint of the original article.

This reprint may differ from the original in pagination and typographic detail.

Please cite the original version. 
The Scandinavian Psychoanalytic Review 40(2): 138-146

\title{
Just a joke. Psychogenesis of humor in alcohol advertisements
}

Janne Seppänen, Matilda Hellman \& Anu Katainen

\begin{abstract}
This article asks what psychic functions humorous alcohol advertisements employ and how they are connected to the wider cultural meanings of alcohol. The material comprises 27 advertisements televised in Europe in 2013. The material is primarily examined using Freud's ideas regarding the psychogenesis of jokes. Freud's conceptions of humor provide in-depth point of views to understand how the advertisements address the viewer's mind. We recognized three psychic processes: the pleasure of nonsense, recognition of the familiar, and liquidation of criticism. We argue that these are essential psychic activities which characterize the more or less unconscious functioning and content of humorous alcohol advertisements. The article suggests that the humorous strategies recall the infantile pleasure connected to playing with language. The humor in alcohol advertisements may also liquidate the critical attitudes toward drinking, enforce the process of denial of addiction and prohibit the reality-based reflection of alcohol use.
\end{abstract}

KEYWORDS: Alcohol advertising, humor, denial, alcoholism, Sigmund Freud

'Humor is reasoning gone mad.'

- Groucho Marx

\section{Introduction}

The purpose of this article is to critically analyze strategies drawn upon when humor is employed in contemporary alcohol advertisements. We understand humor as a powerful mental phenomenon, which works on the threshold between the subject's relation to other people as well as different kinds of media representations, such as advertisements.

In our analyses, the key reference will be Sigmund Freud's famous study Jokes and Their Relation to Unconscious (1905). In his editor's preface, James Strachey notes how the book lies 'somewhat 
apart from the rest of Freud's writings.' He also states how Freud's references to it in the other works are 'comparatively few.' Obviously, the theoretical repercussions of the book are much modest than Freud's major works in this period such as The Interpretation of Dreams (1900) or The Psychopathology of Everyday Life (1901). ${ }^{1}$ However, following Gerard Matte (2001), we think that the analytical power of Jokes has not been fully realized in studies on humor, let alone studies on humorous advertising. It still provides in-depth conceptions to understand how current humorous advertisements address the viewer's psyche.

Humor takes advantage of many unconscious psychic processes, such as denial or regression, which may have vast personal as well as social consequences. We will examine what kinds of psychic functions humorous advertisements utilize in order to address the viewer. By 'addressing' we mean the psychic positions the advertisements provide for the viewer. This is close to what Stuart Hall (1980) has famously described as a hegemonic or preferred reading position.

The key questions are as follows:

- What kinds of psychic functions do humorous alcohol advertisements employ?

- How are these functions connected to the wider cultural meanings of alcohol and drinking?

Today, alcohol advertising establishes a battlefield between stakeholders in public health and the producers, sellers, and marketers of the products (Casswell, 2013; Jahiel \& Babor, 2007). In fact, alcohol advertising has for some time been one of the most inflammable questions in European alcohol policy (Casswell, 2012), and one of the most debated issue has been the need for advertising restrictions. In order to properly ponder the wider social and political issues connected to alcohol it is vital to understand the psychic processes of cultural representations of alcohol, such as advertisements. Obviously, this information is also necessary in order to delineate what kinds of restriction policy is needed, if any.

We have systematically examined televised alcohol commercials in the light of psychoanalytic notions of the psychic and social dynamics of humor. The material was gathered as part of a study on the exposure of minors to alcohol advertising and the contents of the advertising in nine European Union (EU) countries, which was funded by the European Commission (European Commission, 2015).

More specifically, we will scrutinize the following three, often unconscious, psychic dimensions of humor: the pleasure of nonsense, recognition of the familiar, and liquidation of criticism. These all 
are important part of Freud's conception of humor, as well. For the sake of brevity, we will set aside the uses of humor in clinical practices (e.g., Barron, 1999; Mars, 2004) and also psychoanalytic reflections of addiction (e.g., Baldwin, Malone, \& Svolos, 2011). We will begin with a short introduction to some general functions of humor in society and marketing. After introducing our material, we will take a closer look at some key advertisements. Finally, we will draw conclusions and ponder how the commercials and their psychic functions work in the wider social and cultural context of alcohol and drinking.

\section{Humor and advertising}

Humor forms an integral part of face-to-face social interaction as well as media representations. Comedy films, TV sitcoms, and comic books are all funny genres by definition. Humor also works as a flavor in other media genres, such as talk shows, quizzes, and commercials. It has also been an important device for cultural portrayals of almost all aspects of alcohol use, both positive and negative. The fun and amusement of intoxication, comic aspects of drunkards, and poking fun of moralists and temperance are reoccurring themes in art, music, and literature (Abrahamson, 1998; Chen, Grube, Bersamin, Waiters, \& Keefe, 2005). Moreover, 'having fun' is a euphemism for drinking itself, which makes humor a particularly tempting option for advertisers to recruit new consumers and convince old ones to stay loyal to the brand.

Evidently, while humor, jokes, and laughter are closely related, they are different phenomenon and there is no general consensus regarding what humor is. Freud (1905; see also 1927) makes numerous distinctions between comic, humor, and different forms of jokes. As the title suggests, Jokes is mostly about jokes and Freud writes relatively little about humor in general. However, he (1905, p. 229) uses jokes as an illustration of humor, which refers to the fact that as psychic phenomena, jokes, comic, and humor overlap in many ways. In this article, it will not be possible to dig deeper into the manifold definitions of humor and its neighboring conceptualizations (see also, e.g., Martin, 2007). Instead, we will concentrate on the analyses of the advertisements in the light of the abovementioned psychic functions.

In addition to analyzing jokes from the point of view of the intra-psychic dynamic, Freud strongly emphasizes the social and interpersonal character of joking. He (1905, p. 151) writes how 'every joke calls for a public of its own and laughing at the same jokes is evidence of far-reaching psychical conformity.' Hence, it is hardly surprising that some sociologists and social psychologists 
have found Freud's analyses useful and approached humor from various perspectives (see e.g., Kuipers, 2008).

In traditional humor studies, there are three explanatory frameworks to understand the work of humor: incongruity theory, superiority theory, and relief theory (Attardo, 2008, pp. 103-104; Gruner, 2000, p. 12). According to incongruity theory, people laugh at things that are unexpected or otherwise surprising. The laughter arises when expected patterns of behavior are violated, when surprising things happen, or in instances of startling narratives. Absurdity, nonsense, and surprise are vital themes for stimulating amusement. In our research material, many advertisements deployed incongruent narrative elements like absurdity and nonsense, which we will closely analyze in the subsequent sections.

Superiority theory explains laugher by referring to a sense of dominance over other people. The central themes of superiority theory revolve around ridiculing and making fun of others who are less competent or successful or who deviate from norms. Hence, endeavors within the superiority framework often show how hostile and negative stances toward other people are expressed through humor (see also Ruch, 2008, pp. 29-31).

Here, the most relevant approach is relief theory, which states that the enjoyment of humor and laughter arises from the relief of psychic energy, which is also a cornerstone in Freud's thinking. The relief, or redemption, is thought of as both psychological and social. Everybody can recognize a sensation of relief in situations when we find ourselves laughing at the stupidity of our own behavior, for example. The relief is also felt when somebody breaks the ice in a demanding social situation by making humorous remarks. Obviously, relief of psychic energy could also take place in the frameworks of both incongruity and hostility; hence the classification is not mutually exclusive.

It seems that a wide range of humor studies supports the idea that incongruity and play are essential elements of humor (Martin, 2007, pp. 72, 114). To be humorous, a representation - a joke for example - should include a tension between two normally incongruent frames of interpretation, and it should also include a possibility for the resolution of this tension. If the resolution does not work, the representation creates only puzzlement. This incongruence also forms the base for surprise, which is an elementary element in Freud's conceptualizations of jokes. For example, jokes which comprises faulty thoughts, displacements, absurdity etc., all rely more or less combination of incongruent elements which create surprising associations. Good examples are jokes whose technique is based on playing with contrasting interpretations of common words or neologisms 
(e.g., Freud, 1905, pp. 18-19; see also Lacan, 1998, pp. 92-93). (We will present some examples later in this article.)

Being strong and positive mental phenomenon, it is not surprising that humor is widely used in advertising. Marketing researchers have estimated that even $50 \%$ of the television advertisements in the U.S. contain humorous elements (Beard, 2005, p. 54). Humor is also seen as an important strategy to keep contemporary consumers connected to advertisements as they have technical possibilities to exclude advertisements while watching television. van Kuilenburg, de Jong, and van Rompay (2011, pp. 795-796) observed as follows: 'More than ever before, viewers decide for themselves whether or not they want to watch commercials. The use of humor seems a promising way to positively influence that decision.' Moreover, Strick, van Baaren, Holland, and van Knippenberg (2009, p. 1015) conclude that humor has an effect of bypassing the consumer's resistance to persuasion. Interestingly, humor could also be used to mask deceptive advertising. Haseeb Shabbir and Des Thwaites (2007) examined a sample of U.K. television advertisements collected from two major television networks in 2004. They found deceptive claims in $73.5 \%$ of humorous ads, and $74.5 \%$ of these deceptions were masked by using humor. According to Shabbir and Thwaites (2007, p. 81), a high degree of masking 'suggests that advertisers may be using humor to manipulate viewers through mediation of their perception of deceptive claims.'

Marketing studies also suggest that humor is used in advertising because it calls attention to the product, increase comprehension of the commercial, and creates positive attitudes toward the advertisement and the product itself. Nonetheless, humor is also a slightly controversial strategy because it may hurt some people or even create the so-called vampire effect, where captivating humor turns the attention away from the advertised product (Catanescu \& Gail, 2001, p. 92). As marketing researchers have pointed out, it might not be the humor as such that is the problematic element, but rather the kind of humor that is being used and the context in which it is used. For example, van Kuilenburg et al. (2011, p. 809; cf. Madden and Weinberger, 1984; Weinberger and Gulas, 1992, p. 57) found that high-complexity humor that is clearly related to a brand's name was a strong asset that not only attracted viewers' attention to the commercial but also focused their attention on the brand.

\section{Material and methods}

We have analyzed humorous advertisements that were aired in Europe in 2013. The sample of advertisements were selected for the purpose of content analysis in which the aim was to investigate 
whether it could be claimed that minors were specifically targeted by alcohol advertising and to examine whether the contents of advertising were in line with the provisions of the Audiovisual Media Services Directive (AVMSD), which regulates alcohol advertising in European Union. Altogether 450 advertisements were collected from nine EU member states, i.e., 50 from each country, of which a sample of 90 advertisements were selected. The selection was based on the shares of advertisements of different beverage types within one country, and the shares of insertions per brand within beverage types.

The sample thus represents the most frequently advertised beverage types and the campaigns. An analysis grid (variable system) was developed to highlight elements in advertisements which, according to the previous literature, are likely to attract adolescents and which reflect the provisions of the AVMSD. Humor was one of the variables used in the grid. Our analysis showed that of the total material of 90 televised advertisements, almost every third (27) advertisement contained humor as a more or less important feature (European Commission, 2015). These 27 advertisements form the corpus of the material.

We started the analyses by qualitatively cross-reading the material and Freud's conceptions of the psychogenesis of jokes and tried to find interpretative frames that would shed light on the relevant psychic processes. Hence, our examination is grounded both on the theoretical conceptualizations and the contents of the material. As a result of this cross-fertilization, we recognized three closely connected psychic functions or dimensions: the pleasure of nonsense, liquidation of criticism, and recognition of the familiar. These are not the only relevant aspects in the material, but they are very common.

\section{Analyses}

\subsection{The pleasure of nonsense}

A special challenge arose from the multimodality of our material where typical representation is a short ad comprising visual, auditive, and linguistic elements. For Freud, humor, as in the whole practice of psychoanalysis, is primarily a linguistic phenomenon - though in the dream-work pictorial and verbal material are mixed and in constant flux. While in Jokes there are no pictorial, let alone multimodal examples, we hope to show that the abovementioned psychic functions will also work in the analyses of contemporary media representations, such as advertisements. 
In the Freudian framework, linguistic nonsense has its origin in the child's experiments with words when s/he enters into the symbolic structure of the language. The internalizing of language entails a lot of play and experimentation with different significations and sounds of words. In order to obtain a pleasurable effect of rhythm and rhyme, a child 'puts words together without regard to the condition that they should make sense' (Freud, 1905, p. 125). Little by little, the child adapts the correct syntactical and semantic structure and learns to use language. The pleasure of breaking the linguistic rules, however, still remains in adulthood and forms an essential part of humor in social interaction (see also Loose, 2011, p. 5). This is what Freud calls 'pleasure in nonsense.'

This playful and somewhat infantile enjoyment of testing rules of signification seems to hold true not only in the linguistic register but in the other modes of human agency as well. Everybody plays the fool now and then by acting stupidly, speaking nonsense, or laughing at something only for the sake of laughing, as most kids do. Interestingly, Freud (1905, p. 126-127) himself sees intoxication as an example of how adults could gain freedom from the 'pressure of critical reason' and aspire for pleasure in nonsense. From this point of view, nonsensical humor comprises some traits of regression: breaking linguistic norms comprises the possibility of coming close to the pre-symbolic pleasure. In his later essay on humor, Freud (1927, p. 163) recognizes this regressive potential of humor as well as its connection to defense processes, which we will return to later.

In the analyzed advertisements, nonsense appears in absurd linguistic plays, situations, and events, which were always associated with the product and brand. For example, a Finnish long drink advertisement creates a 'stupid' scene where three young men wear very large sombreros and act like heroes in Zapata Westerns. While the closing phrase 'Erittäin kurkosti hoidettu' is impossible to translate, it conveys the feeling of absurdity by transforming the product name (Kurko) into a fake adjective 'kurkosti,' which sounds funny but does not have any meaning at all. In an UK beer advertisement, action hero Jean-Claude Van Damme makes snow angels high in the Alps while badly singing 'Take My Breath Away' (from the movie Top Gun) and wearing a sleeveless denim shirt from the 1980s. In an UK wine advertisement, a man is demonstrating a selection process of quality wines while walking at a winery and in a wine cellar. In the final scene, it is revealed that the man is naked. In these advertisements, humorous nonsense disturbs the norms of verbal expressions, ridicules the action movie genre, and shows the naked truth of cultural distinction. In every advertisement, there is a play of surprising and floating signification with obscure hints of cultural stereotypes, which are in the 'wrong' place. The third example in particular also utilizes incongruence by setting aside contrasting cultural idioms. 
It is not hard to recognize how the scenes resemble dreams in their ability to put strange and incompatible things together to create an enigmatic but emotionally loaded act. In fact, Freud (1905, p. 165) sees a lot of similarities between dream-work and 'joke-work' and claims that 'the characteristics and effects of jokes are linked with certain forms of expression or technical methods, among which the most striking are condensation, displacement and indirect representation,' which are all also well-known functions of dream-work. In the first advertisement, meaningless neologisms (kurkosti) are almost too literal examples of condensation. The action hero making snow angels provides a screen for many kinds of emotional displacements and phantasies. Large sombreros work as indirect representations and metonymies of Zapata Westerns. It is possible to draw the analogy between joke-work and dream-work even further and ponder what would be latent 'joke-thoughts' or even the wish behind the manifest contents of the advertisements.

However, here we are more concerned with how dreamlike nonsense works as a representational strategy in the context of alcohol advertisements. Or, to put the question slightly differently: What is the psychic and social function of the nonsensical form, and not necessarily the singular contents of advertisements?

In the context of advertising, nonsensical form gives the viewer permission to give up strictly coded signification that relies on clear-cut meanings and determined outcomes of communication. Nonsense invites the viewer into an activity that recalls the pleasure of play, which for Freud (1905, pp. 128-129) is the 'first stage of jokes.' However, within the development of her/his critical faculty, the child ceases to play but is not willing to give up the pleasure. Hence, s/he faces the following problem: how 'to avoid criticism and to find the substitute for the mood.' For Freud, jests and jokes begin to work as that kind of substitute. What Freud describes could be seen as a transition of cathexis from one (now prohibited) object to another, which does not challenge one's critical faculty too much. Or, to describe the same as a sociocultural process, the pleasure connected to play finds its place in new domains that are not forbidden from adults. From this point of view, advertising is a huge playground or amusement park for adults with its endless ability to play with meanings, create neologisms, or even make nonhuman objects talk and show emotions. ${ }^{2}$

In Jokes, Freud does not use the concept of pleasure principle, though he devotes a whole chapter to ponder the mechanisms of pleasure. The first mention of the concept takes place in six years later in his paper 'Formulations on the Two Principles of Mental Functioning' (1911). The concept was more thoroughly addressed in the classic essay 'Beyond the Pleasure Principle' (1920) where Freud first time presented the death instinct as something which doesn't fit into the basic functioning of 
pleasure principle, that is, to keep the amount of unpleasure as low as possible. For Freud, death instinct closely relates to the biological force which brings the organism back to the homeostasis with its environment. The logical end point of this process is the decaying of the human organism back to the inanimate state. Jacques Lacan famously rejected the biological foundation of the pleasure principle in favor of the linguistic notion of symbolic order. For him, pleasure principle works as a kind of protection against jouissance which interrupts the symbolic order and threatens the stability of the subject. In his seminar 1957-1958, Lacan (1998, pp. 91-92) accepts Freud's notion of infantile play as a one source of pleasure in nonsensical jokes but connects it to the much wider questions of the development of the demand in the subject's psychic register, where the need (besoin) is restructured and transformed into the desire. In the Lacanian context we can think that nonsense momentarily brings the viewer of the advertisement close to the edge of signification, symbolic order and jouissance but simultaneously brings her/him back to the realm of codified meanings and to the work of the pleasure principle. Even when an advertisement plays with pure nonsense without clear-cut narrative, it is essential that it has some recognizable elements. In the previous Kurko advertisement, a bunch of lads are having fun and talking 'stupid' nonsense, which is a very familiar activity for the target group, mainly working-class boys. The Van Damme beer advertisement would lose a lot of its humorous content if there was not a recognizable protagonist.

\subsection{Recognition of the familiar}

For Freud (1905, p. 120), this return to familiar is also present in the common characteristic of jokes where in each of them 'something familiar is rediscovered, where we might instead have expected something new.' He also thinks that recognition of the familiar is itself always pleasurable. In many jokes, the strength of a punchline comes from the process of recognition of something familiar. In a famous episode from the British TV series Grantchester, one key protagonist, Reverend Sidney Chambers, asks his slightly drunken friend in a bar, 'Geordie, do you think we have a problem with alcohol?' Geordie replies, 'Absolutely, our glasses are empty.' The question creates an expectation of an answer that follows its logic. However, the answer provides a humorous surprise by creating an incongruence with the question itself by showing its contradictory meaning. The punchline relies on the fact that the listener can recognize the meaning of the word 'problem' in both a new and in the most familiar context. The episode is also a typical example of condensation where the two moments of signification collapse into one signifier.

In advertisements, the recognition of the familiar could also work as a sophisticated strategy to sustain gendered signification. A typical example of this is provided by a Finnish beer 
advertisement that works as a playground of gender stereotypes. A young, attractive pair enters the male character's apartment in the late evening, probably after meeting in a bar. The apartment radiates an impression of belonging to a single man that adheres to hegemonic masculine attributes. The decoration consists of a billiard pool table, Viva Zapata posters, heavy leather furniture, and even a sturdy Mastiff. Right after arriving, the man vanishes into the kitchen to get something to drink. Meanwhile, in the living room, the woman produces a hallucinatory fantasy where the whole apartment gradually begins to change to a feminine, traditional domestic-oriented middle-class milieu with flower wallpaper and light colors. Perhaps the most symptomatic transformation takes place when the aggressive Mastiff turns into a small Chihuahua. Nevertheless, when the man reenters the room with two bottles of beer, the fantasy quickly rewinds, and the setting is once again the original masculine decoration.

The transformation of the items from masculine to feminine refers to castration, where the man is stripped from some of his central tokens of power, freedom, and integrity. The turn of the plot saves the man from this unfortunate destiny of becoming a part of a female's realm and fantasy. This is a reoccurring theme in some other commercials in this study, too. A negative change in order occurs when some sort of feminine world is imposing on and threating masculinity: in an UK beer commercial a man is forced to go to a spa by his female spouse. In the spa, he finds other men in a similar subordinated situation. Together they come up with a plan to smuggle beer into the strictly controlled spa premises. Through innovation, skills, and drive, the male protagonists succeed in returning to the original heteronormative state of affairs - a twist that is directly associated with drinking alcohol. The alcohol beverage and the enjoyment of it are connected to the safe sanctuary of uncomplicated traditional male roles and male communities that draw on hegemonic masculinity (see also Connel \& Messerschmiddt, 2005; de Visser \& Smith, 2007).

In the case with the couples in these two beer commercials, it is possible to argue that the final resolution restores the agency to the male protagonist, who enters the scene and manages to take back the familiar command over the situation.

However, the subtler narration takes place in the first commercial portraying a transitory fantasy between two positions (masculine and feminine) where both positions are set into motion such that they momentarily become mixed. Hence, the narration not only protects the masculine identity as untouched and hegemonic, it also shields the binary structure of the gender system where men are men and women are women. The pleasure of the advertisement relies on the familiar tension between the two positions in a context where the binary system of the heterosexual matrix remains 
untouchable. This familiar, generally accepted and hegemonic position is what makes playing with gender possible in the first place. The narratives promote humorous pleasure, which depends on the slightly transgressive fantasy but also on the recognition of the most familiar gender roles.

\subsection{Liquidation of criticism}

Obviously, the recognition of the familiar strongly resonates with the problem of the subversive power of humor - a question that is almost totally beyond Freud's scope. Giselinde Kuipers notes (2008, p. 370) how humor's critical or 'revolutionary' potential depends on power relations between the jokers and their status. In the previously analyzed advertisement, the scene was different. There are no 'jokers' or 'targets' or clear-cut power relations between the protagonists. Instead, playing with gender momentarily challenges the hegemonic masculinity of the heteronormative cultural material upon which it plays but finally drops back to the hegemonic symbolic order. In the advertisement, the 'familiar' refers to common and shared symbolic meanings, which do not challenge the traditional and expect gender roles. The drinker can count on the stability of sticking to the enjoyable habit of drinking beer, described through the stability and order of the two gender worlds being separated. The recognition of the familiar is an essential element of the humor that works for upholding the status quo.

Freud states that an important function of jokes is their ability to undermine criticism: 'The technique which is characteristic of jokes and peculiar to them [...] consists in their procedure for safeguarding the use of these methods of providing pleasure against the objections raised by criticism which would put an end to the pleasure' (Freud, 1905, p. 130). This makes humor powerful in social interaction: 'Where argument tries to draw the hearer's criticism over to its side, the joke endeavors to push the criticism out of sight. There is no doubt the joke has chosen the method which is psychologically the more effective' (1905, p. 133). From this point of view, the humor in advertisements works as a source for regression where the viewer is invited to fantasy scene where s/he happily set aside the critical faculty and gives her/himself a permission to enjoy, though, within the limits of the pleasure principle.

An Austrian beer advertisement depicts a risky scene of two men climbing on mountains. The last man drops but he is connected to the other climber with a rope. The climber is trying to pull the man over the cliff but is unable to do so because the fallen man does not want to lose his grip on his bag full of beer bottles. In the final scene, the hazardous situation is over and the men are having a slightly intoxicated return to the village. 
At the most superficial level, the advertisement takes advantage of Hollywood action films and their dangerous scenes depicting the male bond, loyalty, and an object that has to be protected at all costs. The spectator feels pleasure when s/he recognizes familiar genre and narrative elements. At a subtler level, the advertisement represents a protagonist for whom the alcohol is so precious that he is ready to risk his life in order to save a couple of bottles of beers, which is an obvious sign of addiction. However, this meaning is instantly played off and softened by using humor: Do not take this too seriously; it's just a joke! Interestingly, this form of narration repeats the dynamics of denial where the state of affairs is acknowledged and rejected at the same time. Hence, the crucial meaning of the advertisement is not found in its all-too-familiar pastiche of Hollywood films. The essential message is the form of meta-narration that introduces humor as a means of denial in the context of the addictive substance use. The work of humor as a defense against critical arguments also becomes very clear also in the abovementioned joke from the TV series Grantchester. Geordie's punchline-answer to the question reflects his who-cares attitude and trivializes the serious discussion about alcoholism.

\section{Conclusion: just a joke}

Probably everybody has been a target of joking. Sometimes a joke may hit really hard. The joker may have been stupid or cruel enough to ridicule another person in a manner that targets her/his personal fragilities. In order to get over the situation, the teller may try to soften the effect by saying, 'Hey c'mon, it was just a joke!' (Which usually makes things even worse.) Hence, humor could simultaneously be extremely heavy and light, really serious and playful. This double logic, we will argue, is the logic of advertising in general as well, and serves as one of its strongest armors against serious discussions about its social effects, its sexist and conservative contents, and its general ethics. It is possible to create the harshest campaigns, make exaggerated and even false claims about products, and blatantly deploy consumers' pleasure. However, the bottom line is: it's just a joke!

In consumerist society, alcohol beverages function not only to satisfy thirst or achieve intoxication: they are symbolic tokens related to lifestyles, status, and pleasure. Symbolic meanings attached to the act of consuming alcohol draw on a myriad of images of self- and social fulfilment (McCreanor, Greenaway, Moewaka Barnes, Borell, \& Gregory, 2005, pp. 253-254; Sulkunen, 1998; Törrönen \& Simonen, 2015). The strategies of humor analyzed in this article work in advertising because they also are a self-evident part of our daily interaction. Most people enjoy the slightly regressive pleasure of not-so-serious, playful communication with others. In most cases, we feel joy when we 
unexpectedly recognize familiar things, whether they are people, objects, visual images, or sayings. And it is very easy to undermine a critical effort to discuss something 'rationally' by revealing comical ingredients buried in the discussion or just telling a joke. In most situations, but not all, humor works as the master argument.

The most common euphemism of drinking, 'having fun,' makes an internal, pleasure-orientated and often unconscious connection between humor and drinking. This pleasure may undermine the criticism and inhibit the argumentative discussion, for example, about the dangers of drinking. Humorous alcohol advertisements are part and take advantage of the general narratives connected to drinking. Young people especially show great interest in drinking stories and share them in numerous ways in different social settings, ranging from schools and telephone conversations to chatting on the Internet. Humorous narration forms an essential part of these exchanges (Tutenges $\& \operatorname{Rod}, 2009)$.

The prevalence of playful and nonsensical strategies is also connected to the ambivalences related to the symbolic order of alcohol itself: drinking is a matter of the normal functioning of the society, associated with cultural competence and belonging, but simultaneously intoxication as such always contains the element of transgressing the boundaries of normality (Sulkunen, 2002). This ambivalence manifests itself via cultural norms that govern drinking behavior by indicating the boundaries of socially acceptable and unacceptable behavior. Playing with these norms is likely to be interpreted that the behavior is, in one way or another, problematic, meaning that the element of transgression is always present in the act of drinking. However, the cultural norms that govern drinking behavior are not necessarily self-evident or even unambiguous. They are constantly played out and negotiated in cultural and social processes and intentionally contested by different stakeholders, such as public health advocates and the alcohol industry. The strategies of humor in the advertisements reflect and produce the ambivalences of alcohol consumption and its cultural place by creating transgressive, nonsensical, and playful contexts for alcohol that are detached from the ordinary.

It is obvious that people have very different kinds of resources to face the hilarious logic of these advertisements. It is estimated that in the U.S. 22 million people suffered substance abuse or dependence in 2005. The vast majority of them (15.4 million) abused alcohol, while others misused alcohol and drugs or only drugs. In the same year, nearly 4 million people received treatment for their abuse problem, but only 1.2 million people reported that they are in need of treatment. It is a well-known fact that denial of the problem is one central attribute of alcohol abuse, and it is even 
included in the clinical definition of alcoholism. Addiction researchers state that, 'empirical evidence demonstrates that denial is the number one reason cited by alcoholics for not seeking treatment' (Dare \& Derigne, 2010, p. 182).

Those who do not have addiction or evolving addiction may take humor in alcohol advertisements lightly, as a funny and normal cultural token connected to the temporal pleasure of getting intoxicated. For those who have evolving addiction, the humor may enforce the process of denial and help to bypass the reality-based reflection of their situation.

\section{Notes}

1. Jacques Lacan (1998) provides a detailed reading of Jokes in one of his most important, yet untranslated, seminar Les formations de l'inconscient (1957-1958). It seems that Jokes is relevant for Lacan because it provides a very detailed analyses of verbal techniques of jokes which mounts very well together with Lacan's desire to build a conception of the unconscious drawing to structural linguistics. We will occasionally refer to Lacan's thinking, but the overall analyses will be faithful to the insights presented in Jokes.

2. It should be noted that current studies on humor, which are most often cognitively oriented, also see play as a foundation of humorous experience. As a play, humor is an essential part of everyday social interaction. Humor allows people to temporarily retreat from more or less rational, goalorientated interaction and enjoy playful togetherness and mirth (Martin, 2007, p. 124).

\section{References}

Abrahamson, M. (1998). Humor and mundane reason about alcohol drinking. Nordisk alkohol och narkotikatidskrift, 15, 24-39.

Attardo, S. (2008). A primer for the linguistics of humor. In V. Raskin (Ed.), The primer of humor research (pp. 101-155). Berlin: De Gruyter Mouton.

Baldwin, Y. G., Malone, K. R., \& Svolos, T. (Eds.). (2011). Lacan and addiction: An anthology. London: Karnak.

Barron, J. W. (ed.). (1999). Humor and psyche: Psychoanalytic perspectives. London: The Analytic Press. 
Beard, F. K. (2005). One hundred years of humor in American advertising. Journal of Macromarketing, 25(1), 54-65.

Casswell, S. (2012). Current status of alcohol marketing policy_An urgent challenge for global governance. Addiction, 107(3), 478-485.

Casswell, S. (2013). Vested interests in addiction research and policy. Why do we not see the corporate interests of the alcohol industry as clearly as we see those of the tobacco industry? Addiction, 108(4), 680-685.

Catanescu, C., \& Gail, T. (2001). Types of humor in television and magazine advertising. Review of Business, 22(1), 92.

Chen, M. J., Grube, J. W., Bersamin, M., Waiters, E., \& Keefe, D. B. (2005). Alcohol advertising: What makes it attractive to youth? Journal of Health Communication, 10(6), 553-565.

Connel, R. W., \& Messerschmiddt, J. W. (2005). Hegemonic masculinity. Rethinking the concept. Gender and Society, 19(6), 829-859.

Dare, P. A. S., \& Derigne, L. (2010). Denial in alcohol and other drug use disorders: A critique of theory. Addiction Research and Theory, 18(2), 181-193.

de Visser, R. O., \& Smith, J. A. (2007). Alcohol consumption and masculine identity among young men. Psychology and Health, 22(5), 595-614.

European Commission. (2015) Study on the exposure of minors to alcohol advertising on linear and non-linear audio-visual media services and other online services, including a content analysis. A study prepared for the European Commission by Ecorys, National Institute for Health and Welfare, Centerdata, and GFK. Retrieved April 18, 2016, from https://ec.europa.eu/digital-singlemarket/en/news/study-exposure-minors-alcohol-advertising-tv-and-online-services

Freud, S. (1900). The interpretation of dreams. Standard Edition (Vol. IV-V). London: Vintage Books.

Freud, S. (1901). The Psychopathodology of Everyday Life. Standard Edition (Vol. VI). London: Vintage Books. 
Freud, S. (1905). Jokes and their relation to the unconscious. Standard Edition (Vol. VIII). London: Vintage Books.

Freud, S. (1911). Formulations on the two principles of mental functioning. London: Vintage Books.

Freud, S. (1920). Beyond the pleasure principle. Standard Edition (Vol. XVIII). London: Vintage Books.

Freud, S. (1927). Humor. Standard edition (Vol. XXI, pp. 161-172). London: Vintage Books.

Gruner, C. R. (2000). The game of humor: A Comprehensive theory of why we laugh. New Brunswick: Transaction Publishers.

Hall, S. (1980). Encoding/decoding. In S. Hall, D. Hobson, A. Lowe, \& P. Willis (Eds.), Culture, media, language: Working papers in cultural studies (pp. 117-127). London: Routledge.

Jahiel, R., \& Babor, T. (2007). Industrial epidemics, public health advocacy and the alcohol industry: Lessons from other fields. Addiction, 102(9), 1335-1339.

Kuipers, G. (2008). The sociology of humor. In V. Raskin (Ed.), The primer of humor research (pp. 365-402). Berlin: Mouton de Gruyter.

Lacan, J. (1998). Les formations de l'inconscient. Le séminaire de Jacques Lacan, Livre V. Texte établi par Jacques-Alain Miller. Paris: Éditions du Seuil.

Loose, R. (2011). Modern symptoms and their effects as a form of administration: A challenge to the concept of dual diagnoses and to treatment. In Y. G. Baldwin, K. R. Malone, \& T. Svolos (Eds.), Lacan and addiction: An anthology (pp. 1-39). London: Karnak.

Madden, T. J., \& Weinberger, M. G. (1984). Humor in advertising: A practitioner view. Journal of Advertising Research, 24(4), 23-29.

Mars, R. J. (2004). Jest propelled couch: Humor and play in psychoanalysis. Modern Psychoanalysis, 29(1), 63-76.

Martin, R. A. (2007). The psychology of humor: An integrative approach. Burlington: Elsevier. 
Matte, G. (2001). A psychoanalytical perspective of humor. Humor, 14(3), 223-241.

McCreanor, T., Greenaway, A., Moewaka Barnes, H., Borell, S., \& Gregory, A. (2005). Youth identity formation and contemporary alcohol marketing. Critical Public Health, 15(3), 251-262.

Ruch, W. (2008). Psychology of humor. In V. Raskin (Ed.), The primer of humor research (pp. 17100). Berlin: Mouton de Gruyter.

Shabbir, H., \& Thwaites, D. (2007). The use of humor to mask deceptive advertising'. Journal of Advertising, 36(2), 75-85.

Strick, M., van Baaren, R. B., Holland, R. W., \& van Knippenberg, A. (2009). Why humor breaks resistance to influence: Implicit effects of distraction and positive affect. Advances in Consumer Research, 36, 1015-1016.

Sulkunen, P. (1998). Images and realities of alcohol. Addiction, 93(9), 1305-1312.

Sulkunen, P. (2002). Between culture and nature: Intoxication in cultural studies of alcohol and drug use. Contemporary Drug Problems, 29(2), 253-276.

Törrönen, J., \& Simonen, J. (2015). The exercise of symbolic power by women's magazines from the 1960s to the present: The discursive construction of fields, positions and resources in alcoholrelated texts. Media, Culture and Society, 37(8), 1138-1157.

Tutenges, S., \& Rod, M. H. (2009). "We got incredibly drunk ... it was damned fun”: Drinking stories among Danish youth. Journal of Youth Studies, 12(4), 355-370.

van Kuilenburg, P., de Jong, M. D. T., \& van Rompay, T. J. L. (2011). That was funny, but what was the brand again? International Journal of Advertising, 30(5), 795-814.

Weinberger, M. G., \& Gulas, C. S. (1992). The impact of humor in advertising: A review. Journal of Advertising, 21(4), 35-59.

\section{Author information}

Janne Seppänen is a professor on visual journalism at the The Faculty of Communication Sciences (COMS) University of Tampere, Finland. He is a specialist in visual communication and visual methodologies. He has published seven monographs and over fifty articles. He is the author of The 
power of the Gaze: An introduction to Visual Literacy (2006). Currently, he leads the research consortium Digital Faces (DIFA) funded by the Academy of Finland.

Dr.Soc.Sci., docent (adjunct professor, sociology 2012). Matilda Hellman works as a university researcher at the Department of Social Research. Hellman's research concerns mainly lifestyles and addictions, focusing on how idea world setups are embedded in habits, politics and governance. Typically, her research projects have concerned norms and ideologies in popular, societal and professional constructs, and patterns of such constructs embedded in welfare state systems and cultures.

Dr.Soc.Sci. Anu Katainen works as a University Researcher at the Department of Social Research, Unit of Sociology. She is also part of the University of Helsinki Centre for Research on Addiction, Control and Governance (CEACG) research group. Her research interests relate to the topics such as substance use, alcohol and health policy and health inequalities. 